\title{
Article \\ SPME-GC-MS and FTIR-ATR Spectroscopic Study as a Tool for Unifloral Common Greek Honeys' Botanical Origin Identification
}

\author{
Marinos Xagoraris ${ }^{1}{ }^{\circledR}$, Panagiota-Kyriaki Revelou ${ }^{1}\left(\mathbb{D}\right.$, Stela Dedegkika ${ }^{2}$, Charalabos D. Kanakis ${ }^{1}$, \\ George K. Papadopoulos ${ }^{3}$, Christos S. Pappas ${ }^{1}$ and Petros A. Tarantilis ${ }^{1, *(D)}$ \\ 1 Laboratory of Chemistry, Department of Food Science and Human Nutrition, Agricultural University of \\ Athens, 75 Iera Odos, 11855 Athens, Greece; mxagor@aua.gr (M.X.); p.revelou@aua.gr (P.-K.R.); \\ chkanakis@aua.gr (C.D.K.); chrispap@aua.gr (C.S.P.) \\ 2 Erganal, Food and Environmental Testing Laboratories, Nikita 10, 18531 Piraeus, Greece; \\ destela@outlook.com.gr \\ 3 Laboratory of Plant Breeding and Biometry, Department of Crop Science, Agricultural University of Athens, \\ Iera Odos 75, 11855 Athens, Greece; gpapadop@aua.gr \\ * Correspondence: ptara@aua.gr; Tel.: +30-210-529-4262
}

\section{check for}

updates

Citation: Xagoraris, M.; Revelou, P.-K.; Dedegkika, S.; Kanakis, C.D.; Papadopoulos, G.K.; Pappas, C.S.; Tarantilis, P.A. SPME-GC-MS and FTIR-ATR Spectroscopic Study as a Tool for Unifloral Common Greek Honeys' Botanical Origin Identification. Appl. Sci. 2021, 11, 3159. https://doi.org/10.3390/ app11073159

Academic Editor: Salud Serrano

Received: 2 March 2021

Accepted: 29 March 2021

Published: 1 April 2021

Publisher's Note: MDPI stays neutra with regard to jurisdictional claims in published maps and institutional affiliations.

Copyright: (c) 2021 by the authors. Licensee MDPI, Basel, Switzerland. This article is an open access article distributed under the terms and conditions of the Creative Commons Attribution (CC BY) license (https:// creativecommons.org/licenses/by/ $4.0 /)$.
Abstract: Among the variants of Greek honey, the most commonly available are pine, fir, thyme, and citrus honey. Samples of the above kinds of honey, identified according to European and Greek legislation, were studied using gas chromatography coupled with mass spectrometry (GC-MS) and the attenuated total reflection Fourier transform infrared (ATR-FTIR) spectroscopic techniques. Two chemometric models were developed based on statistically significant volatile compounds (octane; 2-phenylacetaldehyde; 1-nonanol; methyl 2-hydroxybenzoate; 2-(4-methylcyclohex-3-en1-yl); nonanoic acid) and the 1390-945 and 847-803 $\mathrm{cm}^{-1}$ spectral regions, mainly vibrations of fructose and glucose, combined with the stepwise linear discriminant analysis (stepwise LDA) statistical technique. In total, $85.5 \%$ of standard samples, and $82.3 \%$ through internal validation and $88.5 \%$ through external validation, were identified correctly using the GC-MS-stepwise-LDA chemometric model. The corresponding results for the ATR-FTIR-stepwise-LDA chemometric model were $93.5 \%, 82.5 \%$, and $84.6 \%$. The double validation (internal, external) enhances the robustness of the proposed chemometric models. The developed models are considered statistically equivalent, but FTIR spectroscopy is simple, rapid, and more economical.

Keywords: honey; botanical origin; unifloral; authentication; volatile compounds; GS-MS/SPME; ATR-FTIR spectroscopy

\section{Introduction}

In many nations, beekeeping remains an underexploited sector of the agrarian economy. Published sources indicate that the annual production of honey in Greece reaches 21.939 tons, equating to a consumption rate of $1.7 \mathrm{~kg}$ per person [1]. Recently, there has been growing interest in honey exports, and Greece is now the 27th largest honey exporter in the world. Annual levels of value grew by over 14\% from 2015 to 2019, with quantities rising by $18 \%$ during the same period [2]. Greece is one country that has specified the required physicochemical and microscopic characteristics for the main categories of honey. Specific parameters employed for the standardization of monofloral honey are published in the Government Gazette B-239/ 23-2-2005 [3]. All other values of the parameters are listed in Annex II of Article 67 of the Food Code. Nevertheless, honey is a complex natural product; therefore, there are major issues related to authenticity and inherent challenges in this area.

The principal commercially available forms of Greek honey are the pine, fir, thyme, and citrus varieties. The most popular format is pine honey, which comprises $60-65 \%$ of 
overall honey production in Greece. In comparison, citrus accounts for $15 \%$, thyme for $10 \%$, and fir for 5\% [4]. Commercially produced honey is particularly susceptible to adulteration, fabricated declarations of botanical origin, and multiple other forms of fraudulent conduct. This profiteering and deception frequently damage the interests of producers, suppliers, and consumers. Hence, there is a clear need for techniques capable of reliably ascertaining the monofloral botanical origin of honey.

The botanical origin of honey can be determined in accordance with its melissopalynological and physicochemical properties [5-8]. However, these techniques are expensive, time-consuming, and require specialized staff. Authentication of honey can be carried out with different analytical techniques, such as high-performance liquid chromatography with electrochemical detection (HPLC-ECD) [9], stable isotopic analysis [10], nuclear magnetic resonance (NMR) [11], electronic nose [12], and gas chromatography coupled with mass spectrometry (GC-MS) [13] Furthermore, techniques such as Fourier transform infrared (FTIR) [14], near-infrared (NIR) [15], and Raman spectroscopy [16] can also be used. In recent years, there has been a continuous effort to develop more of these techniques coupled with multivariate statistical analysis $[17,18]$.

Among the above techniques, the determination of volatile compounds based on solid-phase microextraction (SPME) coupled with GC-MS has been adopted to identify the botanical origins of Greek honey $[13,19,20]$. Nevertheless, parameters such as polarity fraction, the number of volatile compounds, and chemometric techniques could directly impact the results of discrimination. In addition, there is a growing, constant need to develop practical, reliable, and rapid methods. To the best of our knowledge, there have been no reported studies using total reflectance (ATR)-FTIR spectroscopy for discrimination of Greek honey of different botanical origins.

Multivariate statistical analysis in combination with previously outlined analytical methods could in some cases be a powerful tool for the botanical authentication of honey. To be robust, a statistical model must possess many honey sample standards from every botanical origin, known as a "calibration set", in addition to a "test set" which can be used for validation. Furthermore, the composition of honey means that it is necessary to generate a constant and accurate chemometric paradigm in accordance with monofloral samples, which can be measured against existing legislation.

The aim of the present work was (a) the study of Greek honey samples derived from pine, thyme, fir, and citrus, which were identified according to European and Greek legislation, using SPME-GC-MS and FTIR spectroscopy, and (b) the development of robust chemometric models based on the chromatographic and spectroscopic data for the purpose of differentiating honey samples according to their botanical origin.

\section{Materials and Methods}

\subsection{Samples}

A total of 88 monofloral honey samples from 4 botanical origins (16 pine, 17 fir, 39 thyme, and 16 citrus) were provided directly from beekeepers (2018-2019 harvest years) across Greece under the framework of the research program QuaAuthentic_GR. The monofloral botanical origin of honey samples was confirmed by physicochemical and melissopalynological analysis. Honey samples were analyzed in a short period of time from their receipt; until then, they were kept in the dark at $25^{\circ} \mathrm{C}$.

\subsection{Physicochemical and Melissopalynological Analysis}

The determination of the honey sugars (fructose, glucose, maltose, and sucrose) was performed with an HPLC Shimadzu CTO-10A, equipped with a detector Shimadzu RID20A (Shimadzu Corporation, Kyoto, Japan) according to the official methods of analysis of the Association of Official Analytical Chemists (AOAC) [21]. Additionally, the sum of fructose and glucose was calculated. Electrical conductivity $(\mu \mathrm{S} / \mathrm{cm})$ was determined with a Consort C3010 multi-parameter analyzer, (Consort bvba, Turnhout, Belgium) according to the international honey commission (IHC) [22]. Moisture $(\% w / w)$ was measured using a 
refractometer, (Bellingham \& Stanley Ltd., Kent, UK) and a water bath (Edmund Bühler $\mathrm{GmbH}$, Bodelshausen, Germany) according to IHC [22].

Finally, melissopalynological analysis was performed with a Microscope Krüss (A. Krüss Optronic GmbH, Hamburg, Germany) [23].

\subsection{Isolation of Volatile Compounds}

The isolation of the volatile compounds was performed using the SPME technique. Volatile compounds were isolated, using a triple-phase divinylbenzene/carboxen/polydime thylsiloxane (DVB/CAR/PDMS) fiber 50/30 $\mu \mathrm{m}$ (Supelco, Bellefonte, PA, USA) with a length of $1 \mathrm{~cm}$. Before the experiments, the fibers were conditioned at $270{ }^{\circ} \mathrm{C}$ according to the manufacturer's instructions, using a manual holder. Honey volatile compounds were extracted according to the literature [24] with some modifications: $7 \mathrm{~g}$ of honey was dissolved with $3 \mathrm{~mL}$ of distilled water, and $6 \mathrm{~mL}$ was placed in $15 \mathrm{~mL}$ screw top vials with PTFE/silicone septa. Benzophenone (Alfa Aesar, Kandel, Germany) was used as an internal standard, and a portion of $20 \mu \mathrm{L}$ ( $300 \mu \mathrm{g} / \mathrm{mL}$ in methanol) was added prior to extraction. The vials were kept in a water bath at $60^{\circ} \mathrm{C}$ under stirring, and honey samples were equilibrated for $30 \mathrm{~min}$. Subsequently, the needle of the SPME fiber was inserted into the vial and exposed to the sample headspace followed by a sampling time of $30 \mathrm{~min}$ [24].

\subsection{Analysis of the Isolated Volatile Compounds}

The analysis of volatile compounds was performed using a Trace Ultra gas chromatograph (GC) (Thermo Scientific Inc., Waltham, MA, USA), coupled to a mass spectrometer (MS) (DSQII, Thermo Scientific Inc., Waltham, MA, USA). The desorption conditions were as follows: GC inlet temperature $260{ }^{\circ} \mathrm{C}$ in the splitless mode for $3 \mathrm{~min}$, with a $0.8 \mathrm{~mm}$ injector liner (SGE International Pty Ltd., Ringwood, Australia). The column used was a Restek Rtx-5MS (30 m $\times 0.25 \mathrm{~mm}$ i.d., $0.25 \mu \mathrm{m}$ film thickness) and the carrier gas was helium at a $1 \mathrm{~mL} / \mathrm{min}$ rate. As modified, the oven temperature was adapted to $40{ }^{\circ} \mathrm{C}$ for $6 \mathrm{~min}$, then increased at $120^{\circ} \mathrm{C}$ at a rate of $5{ }^{\circ} \mathrm{C} / \mathrm{min}$, followed by an increment of $3{ }^{\circ} \mathrm{C} / \mathrm{min}$ up to $160^{\circ} \mathrm{C}$ and up to $250^{\circ} \mathrm{C}$ with a step of $15^{\circ} \mathrm{C} / \mathrm{min}$. Finally, the temperature of $250^{\circ} \mathrm{C}$ was kept constant for $1 \mathrm{~min}$ [24]. The transfer line and injector temperatures were maintained at 290 and $220^{\circ} \mathrm{C}$, respectively. Electron impact was $70 \mathrm{eV}$, and mass spectra were recorded at the 35-650 mass range. The peak identification was carried out with the Wiley 275 mass spectra library, its masses spectral data and arithmetic index provided by Adams [25]. Retention index (RI) values of volatile compounds were calculated using n-alkane (C8-C20) standards (Supelco, Bellefonte, PA, USA). Concentrations of the isolated compounds were calculated using the internal standard (benzophenone) and expressed as $\mathrm{mg} / \mathrm{kg}$ of honey.

\subsection{ATR-FTIR Spectroscopy}

FTIR spectra of honey samples were obtained without pretreatment using a Thermo Nicolet 6700 FTIR, (Thermo Electron Corporation, Madison, WI, USA) equipped with a deuterated triglycine sulfate (DTGS) detector. The spectra were in ATR mode with a Horizontal ATR accessory (Spectra-Tech Inc., Stamford, CT, USA) employed with a trapezoid shape $\mathrm{ZnSe}$ crystal $(800 \times 10 \times 4 \mathrm{~mm})$. The crystal provided an angle of incidence of $45^{\circ}$. The speed of the interferometer moving mirror was $0.6329 \mathrm{~mm} / \mathrm{s}$. Spectra were recorded with a resolution of $4 \mathrm{~cm}^{-1}$ and 100 scans. A background spectrum was collected using only ATR crystal, prior to spectrum recording of each sample. Triple FTIR spectra of each sample were obtained, using a different sub-sample each time.

Spectrum processing was performed using the software (OMNIC ver.9.1, Thermo Fisher Scientific Inc., Waltham, MA, USA). ATR-FTIR spectra were recorded in triplicates, smoothed using Savitsky-Golay algorithm, and their baselines were corrected. These pretreatments were performed with "automatic smoothing" (5-point moving second-degree polynomial) and "baseline correction" (second-degree polynomial, twenty iterations) functions. Finally, using the "Statistical Spectra" function, the average of the three spectra 
for each sample was calculated, and each average spectrum was normalized (absorbance maximum value of 1) and saved as a CSV file for further use in the statistical analysis.

\subsection{Statistical Analysis}

The statistical analysis was performed using the SPSS v.25 (IBM, SPSS, Statistics) software. Eighty-eight honey samples were randomly allocated into two groups. The first group of 62 samples (named as "standards"; St1- St62) was used as a calibration set, and the second of 26 samples (named as "unknown"; T1-T26) was used as a test set.

Two chemometric models were developed using the stepwise linear discriminant analysis (LDA) statistical technique. One was based on the GC-MS data and another on ATRFTIR spectra. Each chemometric model was validated using the cross-validation method and with external validation (test set). According to Field, the cross-validation method is more conservative and reliable for the correct classification ability of the samples [26].

\section{Results and Discussion}

\subsection{Physicochemical and Melissopalynological Analysis}

A serious problem in the study of honey is the determination of its botanical origin using objective criteria. For this reason, the European and Greek legislation was used (physicochemical and melissopalynological analysis). The results (Tables S1 and S2) were in agreement with the botanical origin of the honey samples, as has been stated by producers [3].

\subsection{Volatile Compounds Analysis}

Volatile compounds of honey fractions were very complex and involved different classes of chemical compounds. The identified components were 55 including alcohols, acids, aldehydes, ketones, terpenes, hydrocarbons, benzene, and furan derivatives.

Chromatograms of four representative different samples are presented in Figures 1-4. Table S3 shows the isolated compounds. Volatile compounds found mainly in fir honey samples were octane, undecane, nonanal, nonanol, decanal, methyl nonanoate, and nonanoic acid. The main compounds of the volatile fraction of thyme honey samples were benzaldehyde, 2-phenylacetaldehyde, undecane, nonanal, 2-phenylacetonitrile, 1-phenylbutane2,3-dione, methyl nonanoate, 5-isopropyl-2-methylphenol (carvacrol), nonanoic acid, 3hydroxy-4-phenylbutan-2-one, and 3-hydroxy-4-phenylbut-3-en-2-one. The volatile fraction of pine honey samples mainly consisted of undecane, nonanal, nonanol, decanal, methyl nonanoate, and nonanoic acid. The compounds detected in the volatile fraction in citrus honey samples were (2S,5S)-2-methyl-5-(prop-1-en-2-yl)-2-vinyltetrahydrofuran (herboxide), (2S,5R)-2-methyl-5-(prop-1-en-2-yl)-2-vinyltetrahydrofuran (herboxide second isomer), 2-((2S,5R)-5-methyl-5-vinyltetrahydrofuran-2-yl)propan-2-ol, 3,7-dimethylocta-1,6dien-3-ol (linalool), nonanal, (R)-2-((2S,5S)-5-methyl-5-vinyltetrahydrofuran-2-yl)propanal (lilac aldehyde A), (S)-2-((2S,5S)-5-methyl-5-vinyltetrahydrofuran-2-yl)propanal (lilac aldehyde B), (S)-2-((2R,5S)-5-methyl-5-vinyltetrahydrofuran-2-yl)propanal (lilac aldehyde C), (3S,3aS,7aR)-3,6-dimethyl-2,3,3a,4,5,7a-hexahydrobenzofuran; decanal, 2-(4-methylcyclohex3-en-1-yl)propanal (p-menth-1-en-9-al), and methyl 2-aminobenzoate (methyl anthranilate). Many of these compounds have been reported previously to dominate the volatile profile of fir $[27,28]$, thyme $[29,30]$, pine $[4,31]$, and citrus $[29,32,33]$ honey.

\subsection{Spectroscopic Analysis}

Representative spectra from each botanical origin honey sample are presented in Figure 5. The assignments of the major peaks are shown in Table 1 [34-37]. ATR-FTIR spectra consist of two main regions. The first range is between 4000 and $1500 \mathrm{~cm}^{-1}$ (functional group range). The second area ranges between 1500 and $750 \mathrm{~cm}^{-1}$. The spectra were checked for similarity, in the above region, using the OMNIC ver.9.1 software. It was found that the similarity between them is greater than $93 \%$. Statistical processing is therefore necessary. 


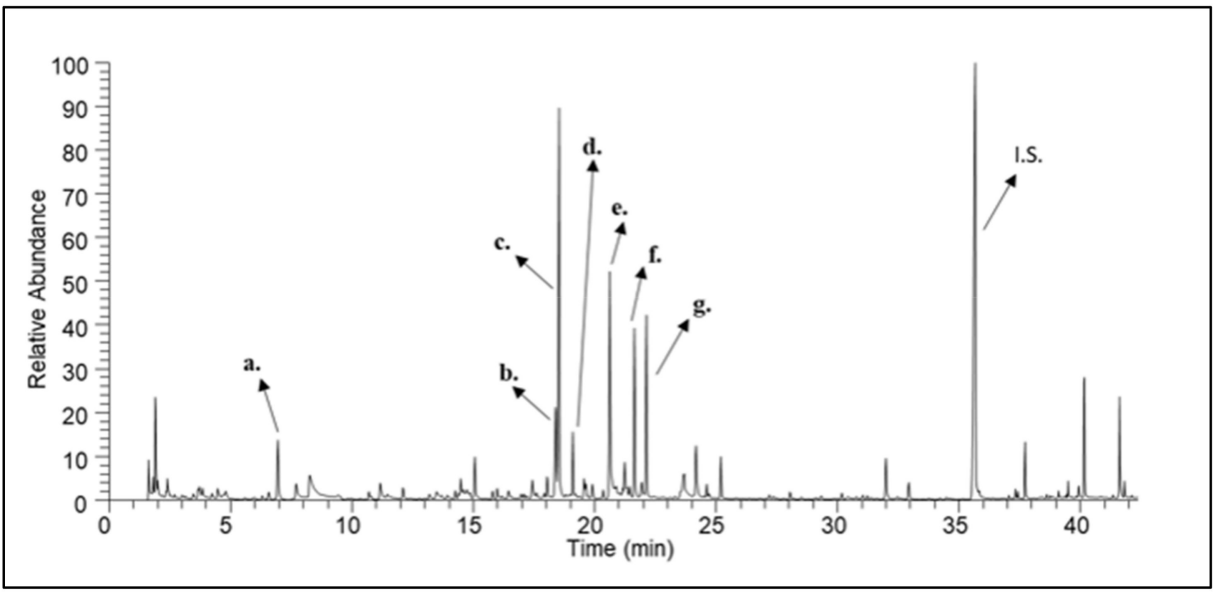

Figure 1. A characteristic gas chromatogram of fir honey. (a) octane; (b) undecane; (c) nonanal; (d) nonanol; (e) decanal; (f) methyl nonanoate; (g) nonanoic acid; (I.S.) Internal Standard.

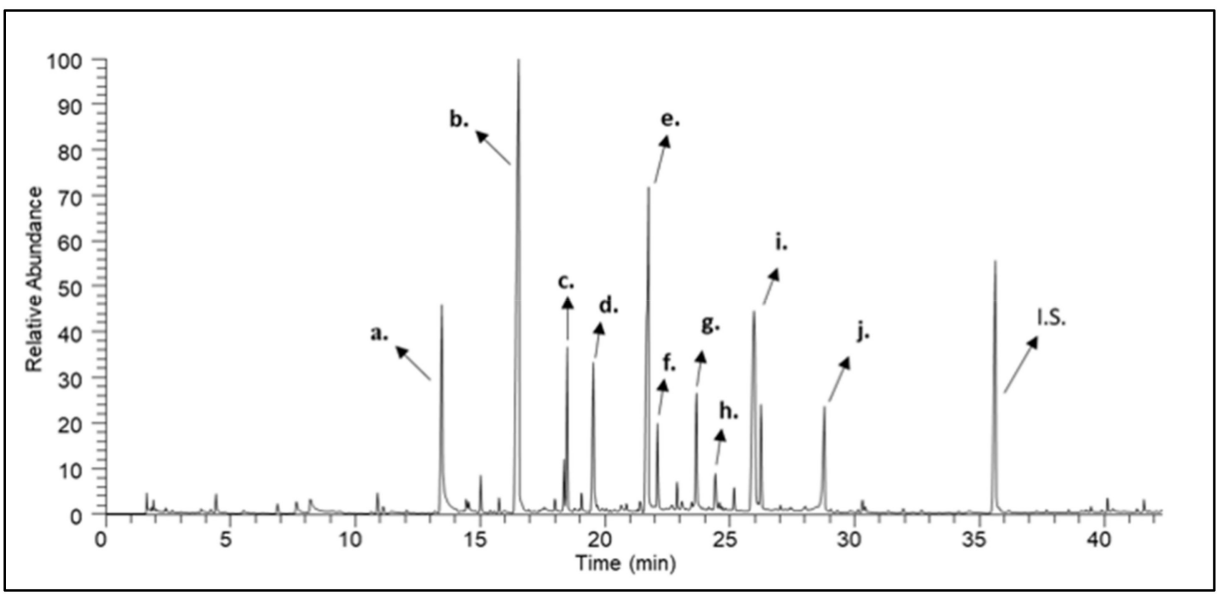

Figure 2. A characteristic gas chromatogram of thyme honey. (a) benzaldehyde; (b) 2-phenylacetaldehyde; (c) nonanal; (d) 2-phenylacetonitrile; (e) 1-phenylbutane-2,3-dione; (f) methyl nonanoate; (g) 5-isopropyl-2-methylphenol (carvacrol); (h) nonanoic acid; (i) 3-hydroxy-4phenylbutan-2-one; (j) 3-hydroxy-4-phenylbut-3-en-2-one; (I.S.) Internal Standard.

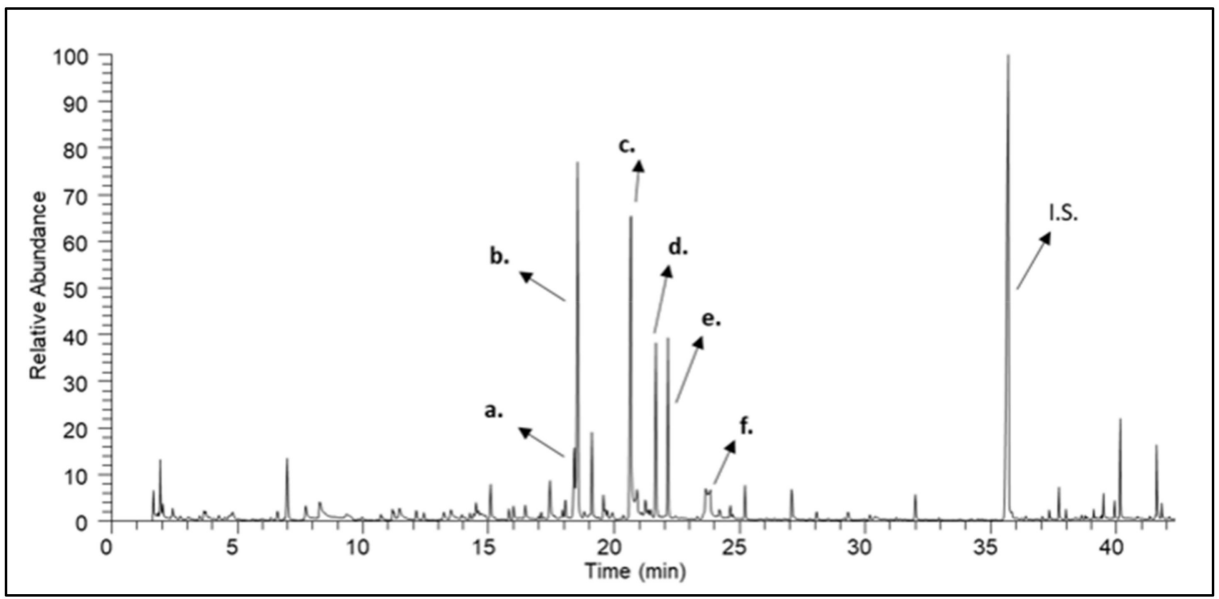

Figure 3. A characteristic gas chromatogram of pine honey. (a) undecane; (b) nonanal; (c) nonanol; (d) decanal; (e) methyl nonanoate; (f) nonanoic acid; (I.S.) Internal Standard. 


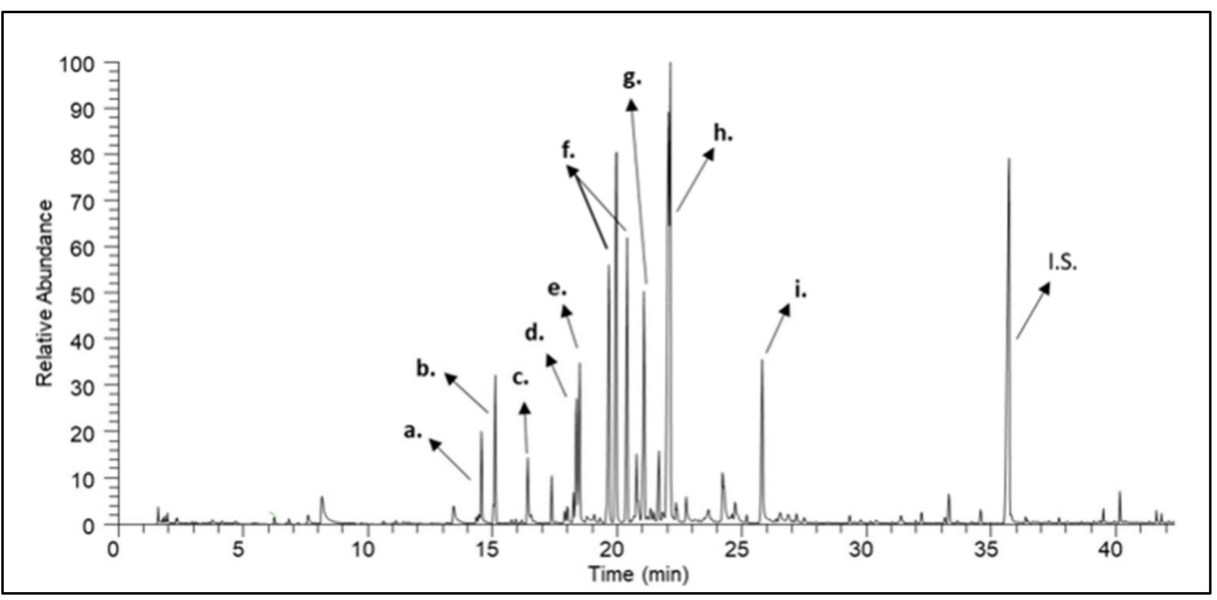

Figure 4. A characteristic gas chromatogram of citrus honey. (a) (2S,5S)-2-methyl-5-(prop-1-en-2-yl)2-vinyltetrahydrofuran (herboxide); (b) (2S,5R)-2-methyl-5-(prop-1-en-2-yl)-2-vinyltetrahydrofuran (herboxide second isomer); (c) 2-((2S,5R)-5-methyl-5-vinyltetrahydrofuran-2-yl)propan-2-ol; (d) 3,7dimethylocta-1,6-dien-3-ol (linalool); (e) nonanal; (f) lilac aldehyde A, B, C; (g) (3S,3aS,7aR)-3,6dimethyl-2,3,3a,4,5,7a-hexahydrobenzofuran; (h) 2-(4-methylcyclohex-3-en-1-yl)propanal (p-menth1-en-9-al); (i) methyl 2-aminobenzoate (methyl anthranilate); (I.S.) Internal Standard.

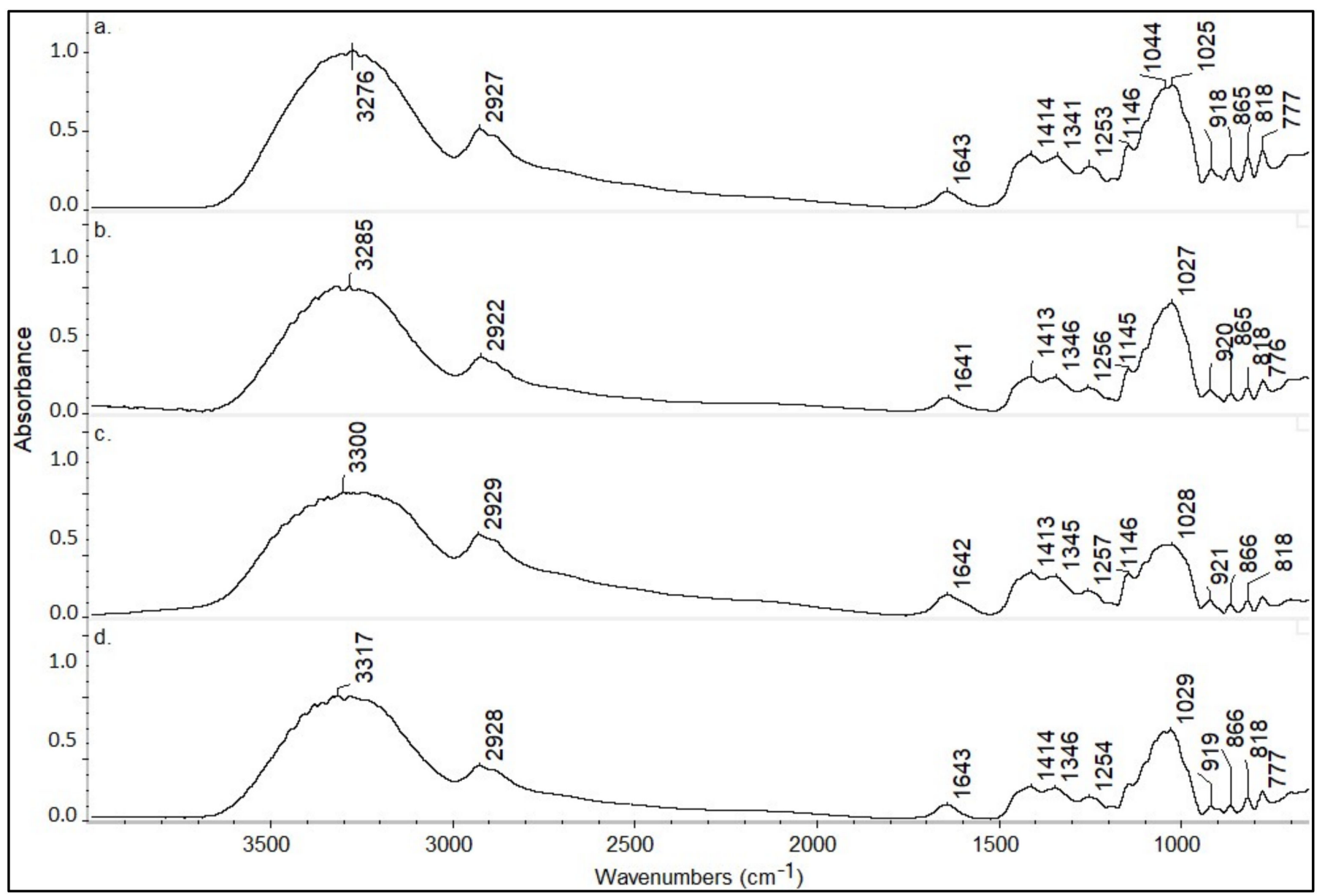

Figure 5. Representative spectra from (a) thyme, (b) pine, (c) fir, and (d) citrus honey samples. 
Table 1. The main peaks and their assignments of the honey samples attenuated total reflection (ATR)-FTIR spectra.

\begin{tabular}{|c|c|c|c|c|}
\hline Wavenumber $\left(\mathrm{cm}^{-1}\right)$ & Functional Group & Peak Performance & Assignment & Reference \\
\hline$\sim 3270$ & $\mathrm{O}-\mathrm{H}$ & Sugars-Water & Stretching & {$[34]$} \\
\hline$\sim 2927$ & $\mathrm{C}-\mathrm{H}$ and $\mathrm{C}-\mathrm{N}$ & Carboxylic acids and Amino acids & Stretching & [34] \\
\hline$\sim 1643$ & $\mathrm{O}-\mathrm{H}$ & Water & Deformation & {$[34]$} \\
\hline$\sim 1414$ & $\mathrm{C}-\mathrm{O}-\mathrm{H},-\mathrm{CH}_{2}$ and $\mathrm{C}-\mathrm{H}$ & Glucose and Alkene & Stretching & [34-36] \\
\hline$\sim 1341$ & $\mathrm{O}-\mathrm{H}(\mathrm{C}-\mathrm{OH})$ & Fructose & Bending & [36] \\
\hline$\sim 1253$ & $\mathrm{C}-\mathrm{C}$ and $-\mathrm{CH}_{2}-$ & Glucose and fructose & Stretching and Bending & [34-36] \\
\hline$\sim 1146$ & $\mathrm{C}-\mathrm{O}, \mathrm{C}-\mathrm{O}-\mathrm{C}$ & Sugars & Bending, Stretching & [36] \\
\hline$\sim 1044$ & $\mathrm{C}-\mathrm{O}(\mathrm{C}-\mathrm{OH}), \mathrm{C}-\mathrm{O}$ & Sugars and fructose & Stretching & [34-37] \\
\hline$\sim 1025$ & $\mathrm{C}-\mathrm{O}$ & Glucose & Stretching & [36] \\
\hline$\sim 918$ & $\mathrm{C}-\mathrm{H}$ & Sugars, Glucose & Bending & [36] \\
\hline$\sim 865$ & $\mathrm{C}-\mathrm{C}$ & Fructose & Stretching & [36] \\
\hline$\sim 818$ & $\mathrm{C}-\mathrm{C}-\mathrm{H}$ & Fructose & Stretching & [36] \\
\hline$\sim 777$ & $\mathrm{C}-\mathrm{C}-\mathrm{H}$ & Fructose & Deformation & [36] \\
\hline
\end{tabular}

\subsection{Stepwise LDA Based on Volatile Compounds Analysis}

Classification of honey samples was carried out using the supervised method of LDA. GC analysis has shown that samples of different botanical origins present both similarities and differences in their volatile composition. Therefore, in order to reach the optimum discrimination results and develop a robust statistical model, it was essential to remove the redundant variables and identify the most significant variables that best discriminate the fir, thyme, pine, and citrus honey samples. For this purpose, stepwise variable selection was applied based on the Mahalanobis distance. Six volatile compounds, octane, 2-phenylacetaldehyde, 1-nonanol, methyl 2-hydroxybenzoate (methyl salicylate), 2-(4-methylcyclohex-3-en-1-yl)-propanal (p-menth-1-en-9-al), and nonanoic acid, were selected from the stepwise algorithm as the most significant for the botanical differentiation of honey samples. We observe that the stepwise procedure eliminated the furan derivatives, which mainly emanate from thermal processing and storage conditions [38-41] and are not related to botanical origin $[38,42]$.

Utilizing the above-selected set of six volatile compounds, LDA was performed where the application of the Wilks "Lambda statistical test for the calibration model evaluation" proved the existence of a significant difference between the means vectors of the four monofloral honey groups (Wilks' Lambda $=0.027$ with $p<0.05$ for the first; 0.164 with $p<0.05$ for the second and 0.656 with $p<0.05$ for the third canonical discriminant function). The calibration model was also confirmed by the eigenvalues. According to the eigenvalues, the first two discriminant functions were significant in the differentiation of honey samples. The first discriminant function recorded the higher eigenvalue (5.142), whilst the second was lower (3.008) and the third was significantly lower (0.524). The canonical correlation for the first discriminant function was estimated at $91.5 \%$, the second at $86.6 \%$, and the third at $58.6 \%$.

The percentage of correct classification of honey samples was $85.5 \%$, while using the cross-validation method enabled $82.3 \%$ of samples to be accurately discriminated (Table 2). In total, from the 26 "unknown" honey samples, 23 (88.5\%) were correctly classified. Classification results indicate that the difference among the rate of correct classification, cross-validation, and external validation set is minimal, which proves the robustness of the statistical model since a large difference indicates the poor performance of the model. Although other studies on botanical discrimination of Greek honey [19,20] present a long distance among pine and fir honey at the discriminant scatter plot. In our study (Figure 6), we observed that fir and pine honey have a small centroid distance, while thyme honey is closer to the pine centroid when compared to the citrus honey that is concentrated farther away. Our findings are confirmed by the literature, as pine and fir honey are honeydew honey share a number of similarities [43]. 
Table 2. Classification results are based on volatile compounds analysis.

\begin{tabular}{|c|c|c|c|c|c|c|c|}
\hline \multicolumn{8}{|c|}{ Classification Results ${ }^{1,2}$} \\
\hline & & \multirow{2}{*}{ Label } & \multicolumn{4}{|c|}{ Predicted Group Membership } & \multirow{2}{*}{ Total } \\
\hline & & & Fir Honey & Thyme Honey & Pine Honey & Citrus Honey & \\
\hline \multirow{8}{*}{ Original } & \multirow{4}{*}{ Count } & Fir honey & 11 & 0 & 3 & 0 & 14 \\
\hline & & Thyme honey & 1 & 18 & 1 & 0 & 20 \\
\hline & & Pine honey & 2 & 0 & 12 & 0 & 14 \\
\hline & & Citrus honey & 0 & 2 & 0 & 12 & 14 \\
\hline & \multirow{4}{*}{$\%$} & Fir Honey & 78.6 & 0.0 & 21.4 & 0.0 & 100.0 \\
\hline & & Thyme honey & 5.0 & 90.0 & 5.0 & 0.0 & 100.0 \\
\hline & & Pine honey & 14.3 & 0.0 & 85.7 & 0.0 & 100.0 \\
\hline & & Citrus honey & 0.0 & 14.3 & 0.0 & 85.7 & 100.0 \\
\hline \multirow{8}{*}{ Cross-validated $^{3}$} & \multirow{4}{*}{ Count } & Fir honey & 11 & 0 & 3 & 0 & 14 \\
\hline & & Thyme honey & 1 & 18 & 1 & 0 & 20 \\
\hline & & Pine honey & 3 & 1 & 10 & 0 & 14 \\
\hline & & Citrus honey & 0 & 2 & 0 & 12 & 14 \\
\hline & \multirow{4}{*}{$\%$} & Fir honey & 78.6 & 0.0 & 21.4 & 0.0 & 100.0 \\
\hline & & Thyme honey & 5.0 & 90.0 & 5.0 & 0.0 & 100.0 \\
\hline & & Pine honey & 21.4 & 7.1 & 71.4 & 0.0 & 100.0 \\
\hline & & Citrus honey & 0.0 & 14.3 & 0.0 & 85.7 & 100.0 \\
\hline
\end{tabular}

${ }^{1} 85.5 \%$ of original grouped cases correctly classified; ${ }^{2} 82.3 \%$ of cross-validated grouped cases correctly classified; ${ }^{3}$ cross validation is done only for those cases in the analysis. In cross validation, each case is classified by the functions derived from all cases other than that case.

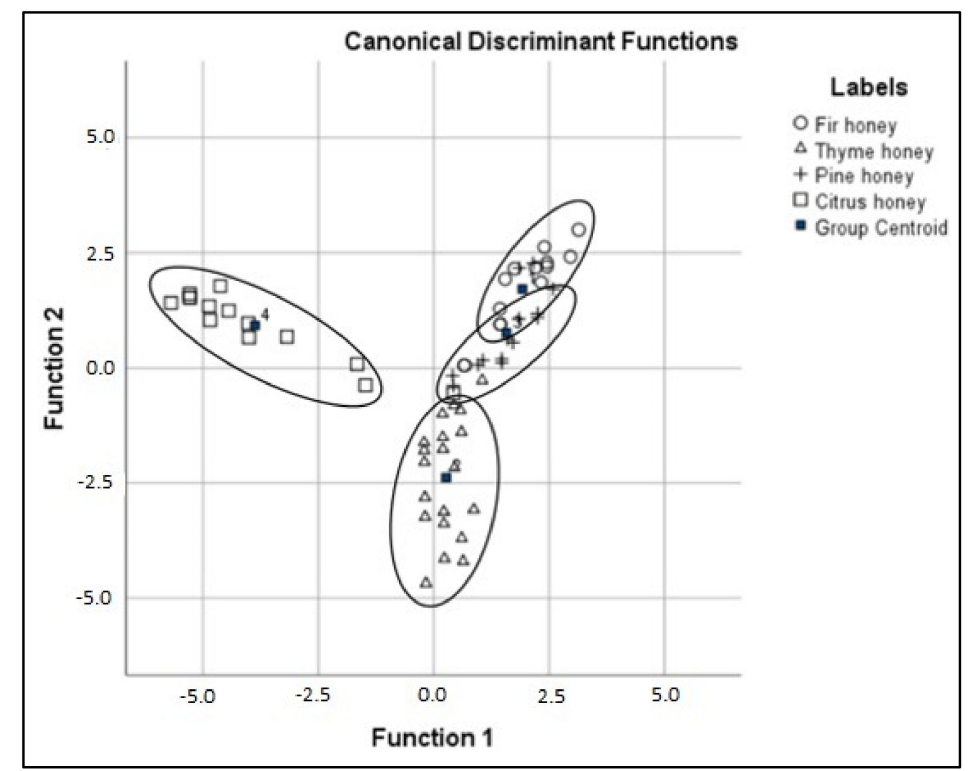

Figure 6. Discrimination results based on volatile compound analysis.

The standardized canonical discriminant function coefficients revealed that two aldehydes were the key volatiles, which can be defined as reliable for the discrimination of the honey groups. In more detail, based on the first discriminant function, the volatile compound 2-(4-methylcyclohex-3-en-1-yl)propanal permitted enhanced discrimination of citrus honey from the other honey groups, while according to the second function, 2-phenylacetaldehyde allowed better discrimination of thyme honey from citrus, pine, and fir honey.

The aldehyde, 2-(4-methylcyclohex-3-en-1-yl)propanal is produced by (E)-8-hydroxylinalool and via the allylic rearranged 8-hydroxygeraniol [44]. Moreover, it has been previously observed in the volatile fraction of monofloral Greek $[13,24,28]$ and Spanish citrus honey [45]. The aromatic 2-phenylacetaldehyde has also been previously reported as a 
characteristic volatile compound identified in the majority of thyme honey samples from Greece [13,46], Italy [47], and Spain [45]. Furthermore, octane, nonanol, and nonanoic acid have been reported as dominant volatile compounds in pine $[4,20]$ and fir [27] honey. Finally, methyl 2-hydroxybenzoate was identified in the majority of the fir honey samples studied; however, according to literature, it has not been previously identified in fir honey.

Karabagias et al. [19] differentiated thyme, pine, citrus, and fir honey samples using 30 volatile compounds as predictive variables, obtaining a classification rate of $86.6 \%$ and a cross-validation rate of $84.0 \%$. In a more recent study, Karabagias et al. [20] differentiated clover, citrus, chestnut, eucalyptus, fir, pine, and thyme honey samples from Greece, Egypt, Spain, and Morocco using 56 volatile compounds with a correct classification rate of $95.4 \%$ and a cross-validation rate of $81.5 \%$. The classification and cross-validation results from other studies are similar; however, in our study, except for cross-validation, we also used an external validation set to confirm the results of the developed statistical model. In addition, other researchers have used a large set of volatile compounds for the classification of honey samples. In our study, we identified key volatile compounds which are directly associated with the botanical origin of honey and eventually will enable the development of analytical methods for application in the industrial setting for the authentication of honey botanical origin.

\subsection{Stepwise LDA Based on ATR-FTIR Spectra}

The development of the calibration model was based on spectral differences in the $1500-750 \mathrm{~cm}^{-1}$ spectral region. From the application of the stepwise algorithm, the statistically significant spectral regions (Figure 7), for the discrimination, were 1390-945 and $847-803 \mathrm{~cm}^{-1}$. The first spectral region was assigned to the stretching vibration of $\mathrm{C}-\mathrm{O}$ and bending of $\mathrm{C}-\mathrm{C}$ and $-\mathrm{CH}_{2}-$ of glucose and fructose. The second was correlated with $\mathrm{C}-\mathrm{C}-\mathrm{H}$ of fructose.

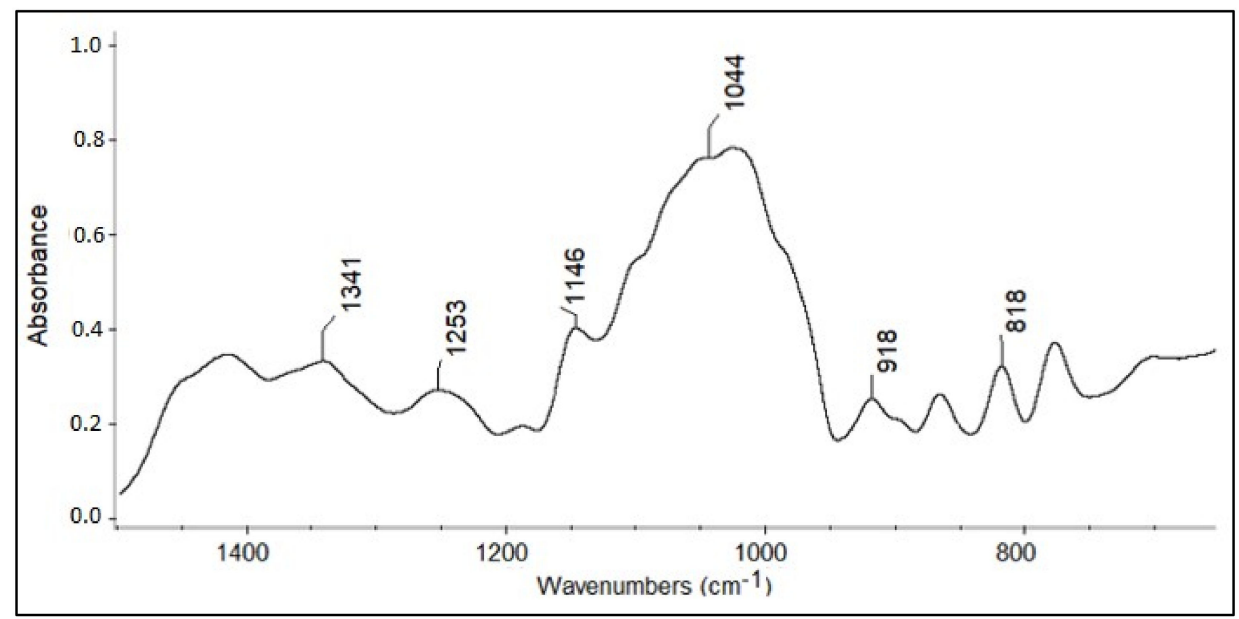

Figure 7. The statistically significant spectral region on which the chemometric model was based for the differentiation of four honey varieties.

Subsequently, the calibration model was performed based on the LDA algorithm. Wilks' Lambda test showed that a significant difference exists between the mean vectors of the four monofloral honey groups (Wilks' Lambda $=0.063$ with $p<0.05$ for the first canonical discriminant function; 0.251 with $p<0.05$ for the second and 0.651 with $p<0.05$ for the third). The eigenvalues of the three discriminant functions (3.021; 1.589 and 0.538$)$ confirmed the calibration model and revealed that the first two discriminant functions were significant for the differentiation of the honey samples, while the values of the corresponding canonical correlations were $86.7 \%, 78.3 \%$, and $59.1 \%$, respectively.

As per the previous results, the discriminant scatter plot (Figure 8) confirmed our current understanding of honey. Thus, $93 \%$ of samples were classified correctly, with 
the cross-validation being $82.3 \%$ (Table 3). Of the 26 "unknown" samples, $84.6 \%$ were identified correctly. From the standardized canonical discriminant function coefficients for ATR-FTIR spectroscopy, several spectral regions responsible for the discrimination of specific honey groups were revealed. While the first function separates thyme honey from fir and pine honey, the second function separates a large percentage of citrus honey from fir honey. Specifically, the functional groups corresponding to the characteristic groups $\mathrm{C}-\mathrm{H}, \mathrm{C}-\mathrm{O}, \mathrm{C}-\mathrm{O}-\mathrm{C}$, and $\mathrm{C}-\mathrm{OH}$ permit more refined discrimination of certain botanical origins with particularly high absolute coefficients, which correspond mainly to the sugars (fructose and glucose). This result could be explained by the fact that blossom honey has a different proportion of sugars from honeydew honey [43].

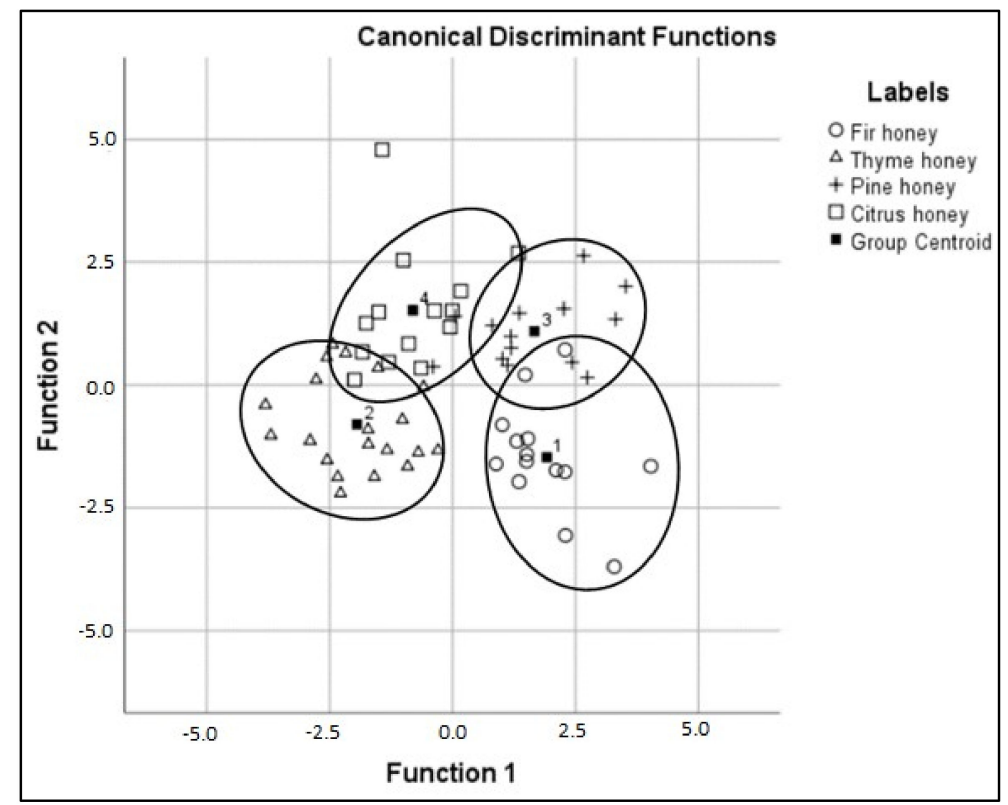

Figure 8. Discrimination results based on FTIR spectroscopy.

Table 3. Classification results based on FTIR spectroscopy.

\begin{tabular}{|c|c|c|c|c|c|c|c|}
\hline \multicolumn{8}{|c|}{ Classification Results ${ }^{1,2}$} \\
\hline & & \multirow{2}{*}{ Label } & \multicolumn{4}{|c|}{ Predicted Group Membership } & \multirow{2}{*}{ Total } \\
\hline & & & Fir Honey & Thyme Honey & Pine Honey & Citrus Honey & \\
\hline \multirow{8}{*}{ Original } & \multirow{4}{*}{ Count } & Fir honey & 12 & 0 & 2 & 0 & 14 \\
\hline & & Thyme honey & 0 & 20 & 0 & 0 & 20 \\
\hline & & Pine honey & 0 & 0 & 12 & 2 & 14 \\
\hline & & Citrus honey & 0 & 0 & 0 & 14 & 14 \\
\hline & \multirow{4}{*}{$\%$} & Fir honey & 85.7 & 0.0 & 14.3 & 0.0 & 100.0 \\
\hline & & Thyme honey & 0.0 & 100.0 & 0.0 & 0.0 & 100.0 \\
\hline & & Pine honey & 0.0 & 0.0 & 85.7 & 14.3 & 100.0 \\
\hline & & Citrus honey & 0.0 & 0.0 & 0.0 & 100.0 & 100.0 \\
\hline \multirow{8}{*}{ Cross-validated $^{3}$} & \multirow{4}{*}{ Count } & Fir honey & 12 & 0 & 2 & 0 & 14 \\
\hline & & Thyme honey & 2 & 17 & 0 & 1 & 20 \\
\hline & & Pine honey & 0 & 0 & 12 & 2 & 14 \\
\hline & & Citrus honey & 0 & 3 & 1 & 10 & 14 \\
\hline & \multirow{4}{*}{$\%$} & Fir honey & 85.7 & 0.0 & 14.3 & 0.0 & 100.0 \\
\hline & & Thyme honey & 10.0 & 85.0 & 0.0 & 5.0 & 100.0 \\
\hline & & Pine honey & 0.0 & 0.0 & 85.7 & 14.3 & 100.0 \\
\hline & & Citrus honey & 0.0 & 21.4 & 7.1 & 71.4 & 100.0 \\
\hline
\end{tabular}

${ }^{1} 93.5 \%$ of original grouped cases correctly classified. ${ }^{2} 82.3 \%$ of cross-validated grouped cases correctly classified; ${ }^{3}$ cross validation is done only for those cases in the analysis. In cross validation, each case is classified by the functions derived from all cases other than that case. 
The LDA algorithm has not been previously applied for the discrimination of the four monofloral honey groups. Gok et al. [18] successfully performed a principal component analysis (PCA) discrimination of eight different honey botanical origins from Turkey. Devi et al. [17] also reported a satisfactory classification among multifloral and monofloral honey when ATR-FTIR was coupled with PCA. Finally, Ciulu et al. [48] applied a random forest algorithm to the classification of 80 samples of asphodel, eucalyptus, thistle, and strawberry tree honey, thereby achieving an average accuracy of $87 \%$ in a cross-validation context.

The findings indicate a high discrimination rate of FTIR spectroscopy in combination with chemometrics as a more powerful authentication tool compared to the developed statistical model based on volatile compounds. The above results highlight the importance of FTIR spectroscopy in combination with chemometrics as an authentication tool with potential application in the industry. This is of great importance as it comprises a rapid, environmentally friendly, and low-cost technique, without the requirement of specialized staff and tedious sample pretreatment.

\section{Conclusions}

Samples of honey (fir, thyme, pine, citrus) of Greek origin, identified in accordance with European and Greek legislation, were studied using SPME-GC-MS and ATR-FTIR spectroscopic techniques. The gas chromatographic and spectroscopic data in combination with the stepwise LDA statistical technique led to the development of two chemometric models for the identifications of their botanical origin. The validation was performed both internally (cross-validation) and externally (test set). The SPME-GC-MS-stepwiseLDA chemometric model is based on six volatile compounds associated with a botanical origin and not with thermal processing or storage conditions. This model recognized $85.5 \%$ of standards, while $82.3 \%$ (cross-validation) and $88.5 \%$ (external validation) of samples were identified correctly. The ATR-FTIR-stepwise-LDA chemometric model was based mainly on the spectral region of sugar absorption, and the corresponding results were $93.5 \%, 82.5 \%$, and $84.6 \%$. The results show that the two chemometric models are equivalent. In addition, considering that identified samples and double validation were used, the chemometric models are considered robust. Comparing the two chemometric models, ATR-FTIR-stepwise-LDA has the advantages of simplicity and speed and is also more economical.

Supplementary Materials: The following are available online at https://www.mdpi.com/article/ 10.3390/app11073159/s1, Table S1: Results of physicochemical analysis. Table S2: Results of melissopalynological analysis. Table S3: Results of volatile compounds isolated from the headspace of fir, thyme, pine, and citrus honey.

Author Contributions: Conceptualization, M.X. and P.-K.R.; methodology, C.D.K., G.K.P., and C.S.P.; software, M.X., P.-K.R., and G.K.P.; validation, S.D.; investigation, M.X. and P.-K.R.; resources, P.-K.R.; data curation, M.X.; writing—original draft preparation, M.X.; writing—review and editing, P.-K.R. and C.S.P.; supervision, C.S.P. and P.A.T.; project administration, P.A.T. All authors have read and agreed to the published version of the manuscript.

Funding: This research has been co-financed by the European Regional Development Fund of the European Union and Greek national funds through the Operational Program Competitiveness, Entrepreneurship and Innovation, under the call "RESEARCH-CREATE-INNOVATE" (Project code: T1E $\Delta K-05678$, by the acronym "QuaAuthentic_GR") awarded to P.A.T. The funders had no role in the study.

Institutional Review Board Statement: Not applicable.

Informed Consent Statement: Not applicable.

Data Availability Statement: Not applicable.

Conflicts of Interest: The authors declare no conflict of interest. 


\section{References}

1. Greek Statistical Authority. Available online: https://www.statistics.gr/el/statistics/agr (accessed on 20 February 2021).

2. Trade Map ITC. Available online: https://www.trademap.org/ (accessed on 20 February 2021).

3. Government Gazette B-239/23-2-2005 Annex II Article 67 of Greek Food Code 2005. Available online: http:/ /www.minagric.gr/ images/stories/docs/agrotis/MeliMelissokomia/KYATaytopoiisi.pdf (accessed on 20 February 2021).

4. Tananaki, C.; Thrasyvoulou, A.; Giraudel, J.; Montury, M. Determination of volatile characteristics of Greek and Turkish pine honey samples and their classification by using Kohonen self organising maps. Food Chem. 2007, 101, 1687-1693. [CrossRef]

5. Marini, F.; Magrì, A.L.; Balestrieri, F.; Fabretti, F.; Marini, D. Supervised pattern recognition applied to the discrimination of the floral origin of six types of Italian honey samples. Anal. Chim. Acta. 2004, 515, 117-125. [CrossRef]

6. León-Ruiz, V.; Vera, S.; González-Porto, A.V.; Andrés, M.P.S. Vitamin C and sugar levels as simple markers for discriminating Spanish honey sources. J. Food Sci. 2011, 76, C356-C361. [CrossRef]

7. Anjos, O.; Iglesias, C.; Peres, F.; Martínez, J.; García, Á.; Taboada, J. Neural networks applied to discriminate botanical origin of honeys. Food Chem. 2015, 175, 128-136. [CrossRef] [PubMed]

8. Jandrić, Z.; Haughey, S.A.; Frew, R.D.; McComb, K.; Galvin-King, P.; Elliott, C.T.; Cannavan, A. Discrimination of honey of different floral origins by a combination of various chemical parameters. Food Chem. 2015, 189, 52-59. [CrossRef]

9. Zhao, J.; Du, X.; Cheng, N.; Chen, L.; Xue, X.; Zhao, J.; Wu, L.; Cao, W. Identification of monofloral honeys using HPLC-ECD and chemometrics. Food Chem. 2016, 194, 167-174. [CrossRef] [PubMed]

10. Dinca, O.R.; Ionete, R.E.; Popescu, R.; Costinel, D.; Radu, G.L. Geographical and botanical origin discrimination of Romanian honey using complex stable isotope data and chemometrics. Food Anal. Methods 2014, 8, 401-412. [CrossRef]

11. Zheng, X.; Zhao, Y.; Wu, H.; Dong, J.; Feng, J. Origin Identification and Quantitative analysis of honeys by nuclear magnetic resonance and chemometric techniques. Food Anal. Methods 2015, 9, 1470-1479. [CrossRef]

12. Gan, Z.; Yang, Y.; Li, J.; Wen, X.; Zhu, M.; Jiang, Y.; Ni, Y. Using sensor and spectral analysis to classify botanical origin and determine adulteration of raw honey. J. Food Eng. 2016, 178, 151-158. [CrossRef]

13. Aliferis, K.A.; Tarantilis, P.A.; Harizanis, P.C.; Alissandrakis, E. Botanical discrimination and classification of honey samples applying gas chromatography/mass spectrometry fingerprinting of headspace volatile compounds. Food Chem. 2010, 121, 856-862. [CrossRef]

14. Svečnjak, L.; Biliškov, N.; Bubalo, D.; Barišić, D. Application of infrared spectroscopy in honey analysis. Agric. Conspec. Sci. 2011, 76, 191-195.

15. Chen, L.; Wang, J.; Ye, Z.; Zhao, J.; Xue, X.; Heyden, Y.V.; Sun, Q. Classification of Chinese honeys according to their floral origin by near infrared spectroscopy. Food Chem. 2012, 135, 338-342. [CrossRef] [PubMed]

16. Corvucci, F.; Nobili, L.; Melucci, D.; Grillenzoni, F.V. The discrimination of honey origin using melissopalynology and Raman spectroscopy techniques coupled with multivariate analysis. Food Chem. 2015, 169, 297-304. [CrossRef]

17. Devi, A.; Jangir, J.; Anu Appaiah, K.A. Chemical characterization complemented with chemometrics for the botanical origin identification of unifloral and multifloral honeys from India. Food Res. Int. 2018, 107, 216-226. [CrossRef] [PubMed]

18. Gok, S.; Severcan, M.; Goormaghtigh, E.; Kandemir, I.; Severcan, F. Differentiation of Anatolian honey samples from different botanical origins by ATR-FTIR spectroscopy using multivariate analysis. Food Chem. 2015, 170, 234-240. [CrossRef]

19. Karabagias, I.K.; Badeka, A.V.; Kontakos, S.; Karabournioti, S.; Kontominas, M.G. Botanical discrimination of Greek unifloral honeys with physico-chemical and chemometric analyses. Food Chem. 2014, 165, 181-190. [CrossRef]

20. Karabagias, I.K.; Karabagias, V.K.; Badeka, A.V. The honey volatile code: A collective study and extended version. Foods 2019, 8, 508. [CrossRef]

21. Helrich, K. Official Methods of Analysis of Association of Official Analytical Chemists, 15th ed.; Helrich, K., Ed.; Association of Official Analytical Chemists: Arlington, VA, USA, 1990; Volume 1.

22. International Honey Commission. Harmonides Methods of the International Honey Commission; Bee Product Science; Bogdanov, S., Ed.; Swiss Bee Research Centre FAM: Bern, Switzerland, 2009. Available online: https://www.ihc-platform.net/ihcmethods2009. pdf. (accessed on 20 February 2021).

23. Louveaux, J.; Maurizio, A.; Vorwohl, G. Methods of melissopalynology. Bee World 1978, 59, 139-157. [CrossRef]

24. Alissandrakis, E.; Tarantilis, P.A.; Harizanis, P.C.; Polissiou, M. Aroma investigation of unifloral Greek citrus honey using solid-phase microextraction coupled to gas chromatographic-mass spectrometric analysis. Food Chem. 2007, 100, 396-404. [CrossRef]

25. Adams, R.P. Identification of Essential Oil Components by Gas Chromatography Quadrupole Mass Spectrometry, 4th ed.; Allured Publishing Corporation: Carol Stream, IL, USA, 2007.

26. Field, A. Discovering Statistics Using SPSS, 3rd ed.; Sage Publications Ltd: London, UK, 2009.

27. Karabagias, I.K.; Dimitriou, E.; Halatsi, E.; Nikolaou, C. Volatile profile, pigment content, and in vitro radical scavenging activity of flower, thyme, and fir honeys produced in Hellas. J. Food Chem. Nanotechnol. 2017, 3, 98-104. [CrossRef]

28. Karabagias, I.K.; Nikolaou, C.; Karabagias, V.K. Volatile fingerprints of common and rare honeys produced in Greece: In search of PHVMs with implementation of the honey code. Eur. Food Res. Technol. 2018. [CrossRef]

29. Alissandrakis, E.; Tarantilis, P.A.; Pappas, C.; Harizanis, P.C.; Polissiou, M. Ultrasound-assisted extraction gas chromatographymass spectrometry analysis of volatile compounds in unifloral thyme honey from Greece. Eur. Food Res. Technol. 2009, 229, 365-373. [CrossRef] 
30. Karabagias, I.K.; Badeka, A.; Kontakos, S.; Karabournioti, S.; Kontominas, M.G. Characterization and classification of Thymus capitatus (L.) honey according to geographical origin based on volatile compounds, physicochemical parameters and chemometrics. Food Res. Int. 2014, 55, 363-372. [CrossRef]

31. Bayraktar, D.; Onoğur, T.A. Investigation of the aroma impact volatiles in Turkish pine honey samples produced in Marmaris, Datça and Fethiye regions by SPME/GC/MS technique. Int. J. Food Sci. Technol. 2011, 46, 1060-1065. [CrossRef]

32. De la Fuente, E.; Martínez-Castro, I.; Sanz, J. Characterization of Spanish unifloral honeys by solid phase microextraction and gas chromatography-mass spectrometry. J. Sep. Sci. 2005, 28, 1093-1100. [CrossRef]

33. Soria, A.C.; Sanz, J.; Martínez-Castro, I. SPME followed by GC-MS: A powerful technique for qualitative analysis of honey volatiles. Eur. Food Res. Technol. 2008, 228, 579-590. [CrossRef]

34. Anjos, O.; Campos, M.G.; Ruiz, P.C.; Antunes, P. Application of FTIR-ATR spectroscopy to the quantification of sugar in honey. Food Chem. 2015, 169, 218-223. [CrossRef]

35. Nayik, G.A.; Dar, B.N.; Nanda, V. Physico-chemical, rheological and sugar profile of different unifloral honeys from Kashmir valley of India. Arab. J. Chem. 2015. [CrossRef]

36. Svečnjak, L.; Prđun, S.; Rogina, J.; Bubalo, D.; Jerković, I. Characterization of Satsuma mandarin (Citrus unshiu Marc.) nectar-tohoney transformation pathway using FTIR-ATR spectroscopy. Food Chem. 2017, 232, 286-294. [CrossRef] [PubMed]

37. Se, K.W.; Ghoshal, S.K.; Wahab, R.A.; Ibrahim, R.K.R.; Lani, M.N. A simple approach for rapid detection and quantification of adulterants in stingless bees (Heterotrigona itama) honey. Food Res. Int. 2018, 105, 453-460. [CrossRef]

38. D'Arcy, B.R.; Rintoul, G.B.; Rowland, C.Y.; Blackman, A.J. Composition of Australian honey extractives. 1. Norisoprenoids, monoterpenes, and other natural volatiles from blue gum (Eucalyptus leucoxylon) and yellow box (Eucaliptus melliodora). J. Agric. Food Chem. 1997, 45, 1834-1843. [CrossRef]

39. Wootton, M.; Edwards, R.A.; Faraji-Haremi, R.; Williams, P.J. Effect of accelerated storage conditions on the chemical composition and properties of Australian honeys 3. Changes in volatile components. J. Apic. Res. 1978, 17, 167-172. [CrossRef]

40. Visser, F.R.; Allen, J.M.; Shaw, G.J. The effect of heat on the volatile flavour fraction from a unifloral honey. J. Apic. Res. 1988, 27, 175-181. [CrossRef]

41. Castro-Vázquez, L.; Díaz-Maroto, M.C.; González-Viñas, M.A.; de la Fuente, E.; Pérez-Coello, M.S. Influence of storage conditions on chemical composition and sensory properties of citrus honey. J. Agric. Food Chem. 2008, 56, 1999-2006. [CrossRef] [PubMed]

42. Bouseta, A.; Collin, S.; Dufour, J.P. Characteristic aroma profiles of unifloral honeys obtained with a dynamic headspace GC-MS system. J. Apic. Res. 1992, 31, 96-109. [CrossRef]

43. Pita-Calvo, C.; Vázquez, M. Differences between honeydew and blossom honeys: A review. Trends Food Sci. Technol. 2017, 59, 79-87. [CrossRef]

44. Bonnländer, B.; Winterhalter, P. 9-Hydroxypiperitone $\beta$-d-Glucopyranoside and Other Polar Constituents from Dill (Anethum graveolens L.) Herb. J. Agric. Food Chem. 2000, 48, 4821-4825. [CrossRef]

45. Castro-Vázquez, L.; Díaz-Maroto, M.C.; González-Viñas, M.A.; Pérez-Coello, M.S. Differentiation of monofloral citrus, rosemary, eucalyptus, lavender, thyme and heather honeys based on volatile composition and sensory descriptive analysis. Food Chem. 2009, 112, 1022-1030. [CrossRef]

46. Karabagias, I.K.; Halatsi, E.Z.; Kontakos, S.; Karabournioti, S.; Kontominas, M.G. Volatile fraction of commercial thyme honeys produced in Mediterranean regions and key volatile compounds for geographical discrimination: A chemometric approach. Int. J. Food Prop. 2016, 20, 2699-2710. [CrossRef]

47. Piasenzotto, L.; Gracco, L.; Conte, L. Solid phase microextraction (SPME) applied to honey quality control. J. Sci. Food Agric. 2003, 83, 1037-1044. [CrossRef]

48. Ciulu, M.; Oertel, E.; Serra, R.; Farre, R.; Spano, N.; Caredda, M.; Malfatti, L.; Sanna, G. Classification of unifloral honeys from SARDINIA (Italy) by ATR-FTIR spectroscopy and random forest. Molecules 2021, 26, 88. [CrossRef] [PubMed] 